\title{
CFRP の熱サイクル劣化特性
}

\author{
中 野 詔 彦*長谷川澄子** \\ Degradation Characteristic of CFRP by Heat Cycle \\ by \\ Nobuhiko NAKAnO* and Sumiko HASEGAWA**
}

A heat cycle test equipment was designed and assembled, and it was used to perform the fatigue test of CFRP as one of the environmental element tests for evaluating the durability of composite materials in thermal environments. The main results obtained are as follows.

(1) For CFRP, lowering of flexure strength was most remarkable in the environment comparable to the condition on the fracture critical curve of stress-temperature, when subjected to heat cycle fatigue under creep stress.

(2) The maximum degradation was found when the high temperature side of the heat cycle temperature range was near $T_{g}$.

(3) The degradation of CFRP with heat cycle fatigue indicated the following behaviors depending upon the combination of stress and temperature range.

(a) Type showing a remarkable degradation in the early stage.

(b) Type showing a gradual degradation.

(c) Type showing little degradation in the early stage.

キー・ワード : CFRP, 熱サイクル疲労, 忘力負荷, 曲げ強度

\section{1 緒訔}

複合材料の耐環境性に関する基礎資料はほとんぞ集 積されていず，環境劣化挙動の把握和よび耐環境性評 価技術の確立は, 当材料が今後, 宇宙, 航空, 海洋等 に新材料として活用される上の大きな課題となってい る. 大気圏, 宇宙圈の特殊な環境に暴露される複合材 料の劣化挙動を明らかにするととるに，実環境暴露と 等価な模擬環境による促進試験法および而環境性評価 法を確立することを目標に, 環境要素の模擬試験装置 のひとつとして熱サイクル疲労試験機を設計試作した. 複合材料の熱サイクル試験の実施例はあるが，無負荷 条件によるもので促進效果がない，実環境中で用いら れる材料は，多かれ少なかれ応力負荷状態で使用され ている. 本試作機は, 応力負荷状態で熱サイクル試験 を行らことを特徵としており，ここでは本試作機によ る CFRP の劣化挙動を曲げ強度の変化から検討した 結果について報告する.

$$
2 \text { 実験 }
$$

\section{$2 \cdot 1$ 試料}

試料の CFRP には炭素纎維 として高強度系の市販 品（東レ製 T-300）を用い, マトリックスとして, ビ スフェノール系エポキシ樹脂を用いた. 樹脂の $T_{g}$ は $143^{\circ} \mathrm{C}$ (TMA 法), 比重は 1.211 , 曲げ強度は 14.2 $\mathrm{kg} / \mathrm{mm}^{2}$, 曲げ弾性率は $302 \mathrm{~kg} / \mathrm{mm}^{2}$ であった. CFRP は, 厚さ $3 \mathrm{~mm}$ の一方向強化材料で, 繊維充てん率は $V_{f}: 60 \%$ ものを用いた.

\section{$2 \cdot 2$ 熱サイクル疲労試験機の試作}

実環境中で使用される材料は, 多かれ少なかれ荷重 条件下で熱サイクルを受けている. 耐環境性試験法と しての要件は, 促進性と実環境類似性である. 促進性 とともに実環境類似性の面で材料の使用条件の多様性 に対応できる装置が要素試験としても必要であり, そ れらの点に留意して設計試作した. Fig.1 に試作した 熱サイクル疲労試験機の概観図を示し, Fig. 2 に冷却 槽および試験槽と冷凍機の関係を示した。冷却槽 (Fig. 2 の右側の槽で, Fig. 1 では試験槽の後側となってい る）拉よび試験槽（Fig.2 の左側, Fig. 1 の正面）の 二槽からなり，ヒータは Fig.1 のDに示すよらに試 験槽に取り付けられている. 二槽間のシャッターの開 閉を Fig. 2 のDにより行い，Fig.1 の $A_{1}, A_{2}$ およ び Fig. 2 のCにより急激な熱サイクルがスムーズに でさるよらに工夫されている，温度幅は $-50^{\circ} \mathrm{C}$ から $250^{\circ} \mathrm{C}$ 範囲でサイクル時間とともにコントロールパ ネル $\mathrm{H}$ で操作することにより任意に設定できる. 温度 上昇時間は, 最も速い場合は $-50^{\circ} \mathrm{Cから} 250^{\circ} \mathrm{C}$ の間を 30 分, 温度降下時間は, 最も速い場合で $250^{\circ} \mathrm{C} ら-$

$\dagger$ 原稿受理 昭和60年6月17日 Received June 17, 1985

* 正会 員 織維高分子材料研究所 茨城県筑波郡谷田部町東, Research Institute for Polymers and Textiles, Yatabe-Higashi, Tsukubagun, Ibaraki

** 瀻維高分子材料研究所 茨城県筑波郡谷田部町東, Research Institute for Polymers and Textiles, Yatabe-Higashi, Tsukuba-gun, Ibaraki 
$50^{\circ} \mathrm{C}$ まで60分である. 試料 Jには, テニによる引張負 荷方式で，三点曲げあるいは引張荷重が最大 1 トンま でかけられる. 本実験では, Fig.1 の試験槽内の治具 に示されるように三点曲げ荷重をかけて試験を行った が，治具を交換することにより引張荷重もかけること

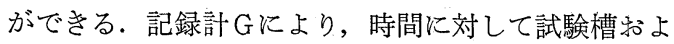
び冷却槽内の温度が記録でき, Eより発生する試料の 変位量も記録できる，変位測定範囲は最大 $20 \mathrm{~mm}$ で 最小は $0.01 \mathrm{~mm}$ である. また試験槽と冷却槽の間の シャッターの上方部を閉じて下方部を開いたままの状 態にしてすなわち Fig.1 の $A_{1}$ を閉じて $A_{2}$ を開い たままの状態にして， $A_{2}$ の部分に試料をつけたパネ ルをとりつけることにより, 設定範团内で試料の両面 飞熱こう配を与兄ることが可能になっている. Fig.1 のIは冷凍装置であり, その詳細は Fig. 2 に示して

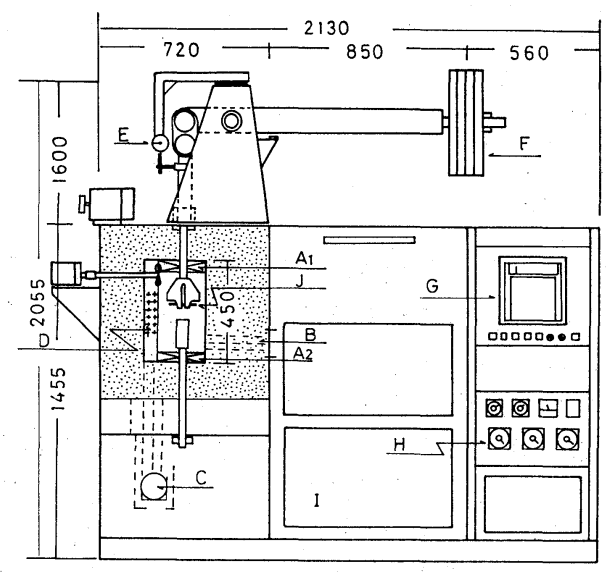

Fig. 1. A heat cycle fatigue test equipment which has been assembled for trial.

$A_{1}$ : cold air blowoff, $A_{2}$ : cold air drawning, $B$ : exhaust port, $\mathrm{C}$ : exhaust air blower, $\mathrm{D}$ : heater, $\mathrm{E}$ : strain gauge, $\mathrm{F}:$ load, $\mathrm{G}$ : recorder, $\mathrm{H}$ : control panel, I : freezer, $J$ : specimen

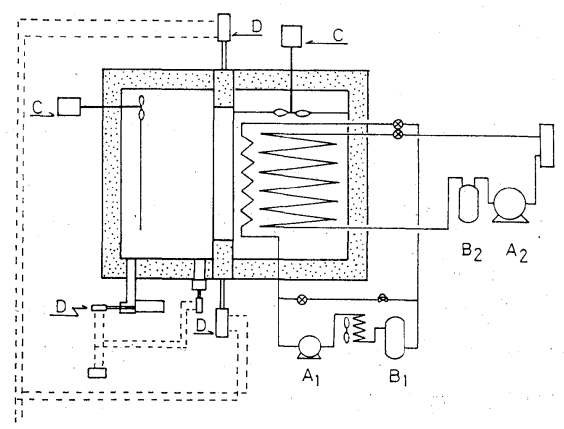

Fig. 2. Test room, freezing room and freezer of heat cycle fatigue test equipment:

$A_{1}$ : high temperature freezer, $A_{2}$ : low temperature freezer, $B_{1}:$ high temperature cold medium, $B_{2}$ : low temperature cold medium, $C:$ fan, $D:$ air valve
いる. Fig. 2 亿示すように, 本装置の冷却方式は, 低 温用の冷媒 $B_{2}$ 之冷凍機 $A_{2}$ 扝よび高温用の冷媒 $B_{1}$ と冷凍機 $\mathrm{B}_{1}$ を用いた二元冷凍法を採用して構造を簡 単にし冷凍能率をあげている. また極低温用の冷媒ガ スは常温以上より使用する場合には, 圧縮機に異状加 熱, 負荷がかかりノッキング現象が生じ冷涷機にトラ ブルが発生するが，本装置は冷凍機保護回路を採用し て，異状を防止している. Fig. 3 亿本試駼機の時間と 温度の変化の関係の一例およびそのときの CFRP の たわ量の変化を示した。 $-50^{\circ} \mathrm{Cから} 250^{\circ} \mathrm{C}$ の熱サイ クルの場合で温度上昇時間 30 分, 下降時間 60 分でー

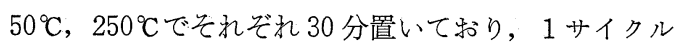
150分である. 試料流, $14 \mathrm{~kg} / \mathrm{mm}^{2}, 21 \mathrm{~kg} / \mathrm{mm}^{2}$ の 曲げ荷重を負荷している，温度变化に対応してたわみ 量がサイクリックに変化して和り，材料がこのために 疲労劣化を和こするのと思われる。

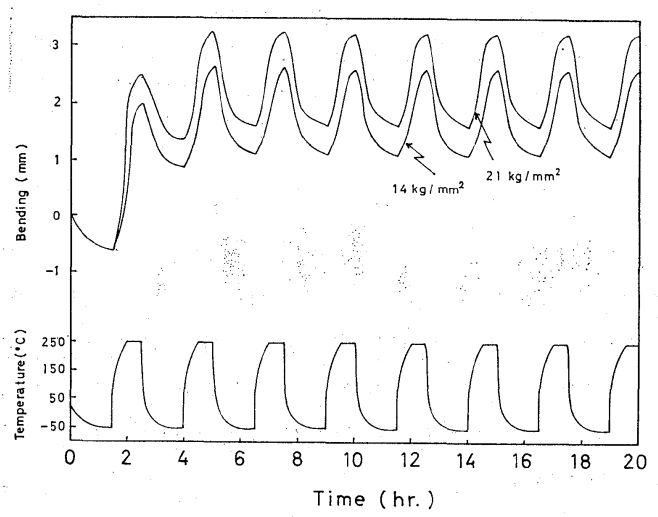

Fig. 3. Temperature cycles and bending cycles of $\mathrm{CFRP}$ in heat cycle fatigue test equipment.

\section{$2 \cdot 3$ CFRP の疲労試験}

本実験に打いては, 長さ $70 \mathrm{~mm}$, 幅 $10 \mathrm{~mm}$ の短ざ く片を CFRP 板より切り出して試料とした. 支点間 距離 $50 \mathrm{~mm}$ の三点曲げ荷重をかけて，1 サイクル150 分で，温度上昇速度，下降速度を上記の条件で与光， 温度幅, 荷重, サイクル数を変化させたときの曲げ強 度保持率の変化をインストロン試験機を用いて検討し た. 曲げ強度は, 三点曲げ試験で測定した. 支点間距 離は $50 \mathrm{~mm}$ でひずみ速度は $1 \mathrm{~mm} / \mathrm{min}$ であった。

\section{$3 \cdot 1$ 破壊限界曲線}

\section{3 結果および考察}

Fig. 4 は $-50 \sim 250^{\circ} \mathrm{C}$ 温度幅で, 負荷荷重を変化 させたときの，時間と曲げたわ又量の関係を示したも のである. 荷重が大きいと短時間でクリープ破壊を生 ずる. 荷重 $22 \mathrm{~kg} / \mathrm{mm}^{2}$ までは1サイクルをまたずに クリープ破断を生ずる．荷重 $21 \mathrm{~kg} / \mathrm{mm}^{2}$ 以下になる と，切断しないでサイクリックなひずみの変化を生ず 


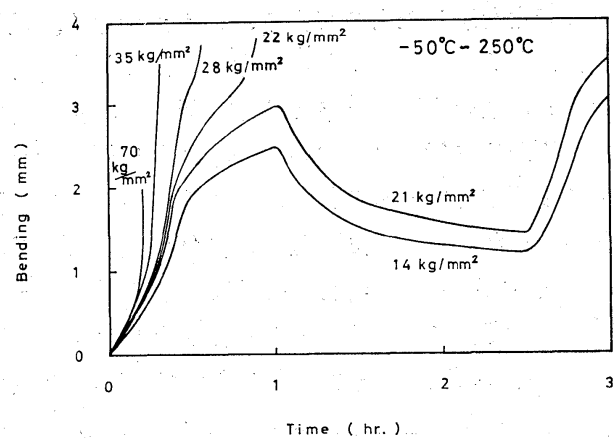

Fig. 4. Fracture critical stress of CFRP at -50 $\sim 250^{\circ} \mathrm{C}$.

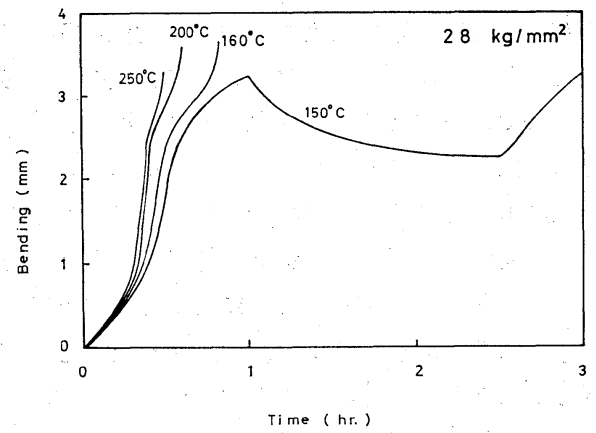

Fig. 5. Fracture critical temperature of CFRP at $28 \mathrm{~kg} / \mathrm{mm}^{2}$.

る。荷重が小さくなるとひずみ量も小さくなりサイク リックな変化を生ずる．切断しないでサイクリックな 変化を生ずる限界の荷重（この場合は $21 \mathrm{~kg} / \mathrm{mm}^{2}$ )を 破壊限界荷重と呼ぶ. Fig. 5 は, 荷重を $28 \mathrm{~kg} / \mathrm{mm}^{2}$ と一定にして，温度幅を変化させたときの時間と曲げ たわみ量の変化を示したものである. 図中の数字は一 $50^{\circ} \mathrm{C}$ からの温度までの温度幅を示したものであり， ー50〜 $160^{\circ} \mathrm{C}$ の温度幅までは，サイクリックなたわみ 量の変化を生ずる前に切断してしまらが， $-50{ }^{\circ} \mathrm{C}$ か ら $150^{\circ} \mathrm{C}$ の温度幅では切断しないでサイクリックなた わみ量の変化を生ずる. 切断しないでサイクリックな

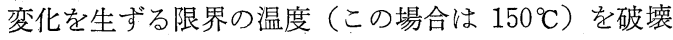
限界温度と呼ぶ。このようにして, 各温度幅, 荷重に 対して，破壊限界荷重，破壊限界温度を求め，Fig. 6 に示すような荷重一温度の破壊限界曲線を求めた。 温 度に対して荷重はS字曲線を示して低下して扣り，そ の变曲点は, CFRP のマトリックス樹脂の $T_{g}\left(143^{\circ} \mathrm{C}\right)$ に依存していることが示唆される. Fig. 7 は破壊限界 曲線上の荷重, 温度幅で10サイクルの熱サイクル疲労 を与えたときの $-50^{\circ} \mathrm{C}$ かの温度幅と曲げ強度保持率 の関係を示したものである，温度幅が大きくなるに従

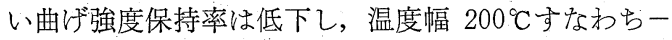
50 $150^{\circ} \mathrm{C}$ に和汀る劣化が最も大きく，曲げ強度保持

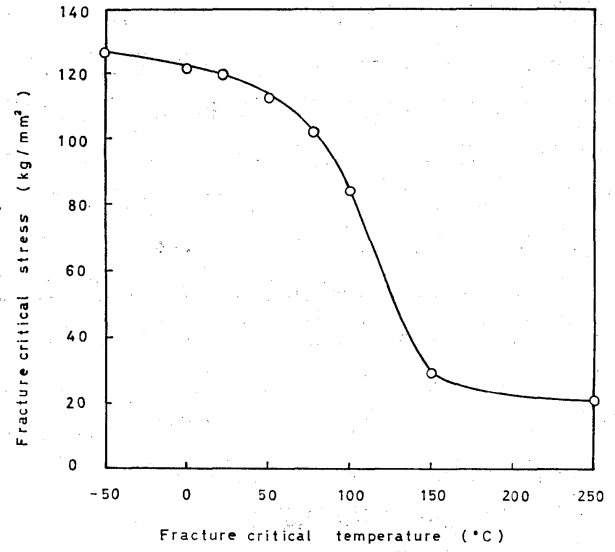

Fig. 6. Fracture critical curve of stress-temperature of CFRP.

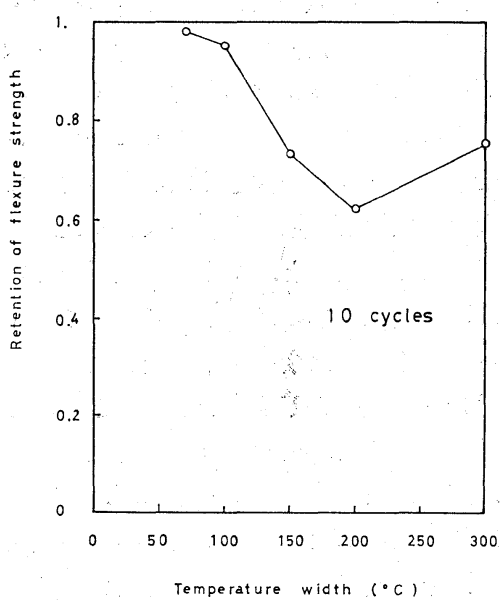

Fig. 7. Relation between the temperature width and the retention of flexure strength of CFRP at 10 cycles on fracture critical curve.

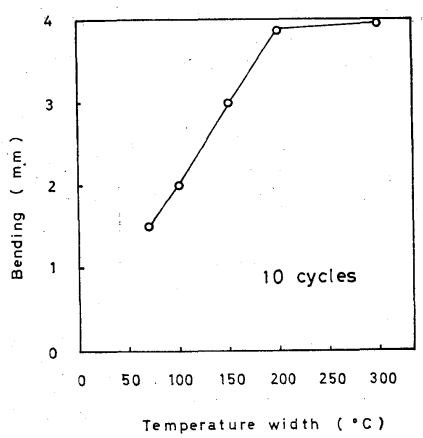

Fig. 8. Relation between the temperature width and the bending of CFRP at 10 cycles on fracture critical curve.

率の極小を示す，温度幅がそれよりも大きくなるとむ しろ曲げ強度保持率は大きくなる，このことは， $\mathrm{CF}$ $\mathrm{RP}$ の熱サイクル劣化挙動がマトリックスの $T_{\boldsymbol{g}}$ に依 存していることを示している. Fig. 8 は同様に破壊限 
界曲線上の荷重, 温度幅で10サイクルの熱サイクル疲

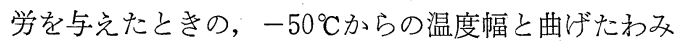
量との関係を示したものである. 温度幅が増加するに 従いたわみ量は増加する. 温度幅 $200{ }^{\circ} \mathrm{Cすなわちー50}$ 〜 $150^{\circ} \mathrm{C}$ の温度幅までは, たわ名量は直線的に増加し, その後はほぼ一定となる。すなわち, 破壊限界線上に 扣ける劣化は, たわ及量に依存し, たわ及量の増大に 従い曲げ強度保持率が低下するものと思われる. 温度

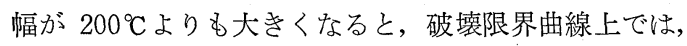
ひずみ量がそれ以上に増加できなくなるので, 曲げ強 度保持率に極小が生ずるものと思われる.

\section{$3 \cdot 2$ 曲げ強度保持率の変化}

温度幅および負荷荷重の相違による曲げ強度保持率 の変化をサイクル数に対して検討した.

Fig. 9 はー50 $250^{\circ} \mathrm{C}$ の温度幅で, 荷重 $14 \mathrm{~kg} / \mathrm{mm}^{2}$, および $21 \mathrm{~kg} / \mathrm{mm}^{2}$ 負荷したときのサイクル数に対す る曲げ強度保持率の変化を示したものである. 荷重が 小さい場合には, サイクル数に対して初期には汷とん ぞ変化せずサイクル数が大きくなると劣化してくる. 荷重が大きくなると初期の劣化が大きくなり, 限界曲 線上に載るようになると, サイクル数が小さい領域で 急激な曲げ強度保持率の低下が生じ, サイクル数が大 きくなってもその值は余り変化しない. Fig.10は一 $50 \sim 150^{\circ} \mathrm{C}$ 温度幅で負荷荷重を変化させたとさのサ イクル数に対する曲げ強度保持率の変化を示したもの である. 応力が限界曲線上にある $28 \mathrm{~kg} / \mathrm{mm}^{2}$ のとき は, 曲げ強度保持率はサイクル数の小さい領域で急激 に低下し, その後の変化はほとんどない. 負荷荷重が $21 \mathrm{~kg} / \mathrm{mm}^{2}$ になると, 曲げ強度保持率は徐々に低下 するよらになる，さらに負荷荷重を小さくして $14 \mathrm{~kg} /$ $\mathrm{mm}^{2}$ にすると，10 サイクル程度まではほとんど曲げ 強度保持率は変化せず，20サイクルでやや減少する程 度である. Fig. 11は， - 50〜 $100{ }^{\circ} \mathrm{C}$ の温度幅における
同様の変化を示したものである. 荷重が大きく, 限界 曲線上にある $84 \mathrm{~kg} / \mathrm{mm}^{2}$ のときは，曲げ強度保持率 はサイクル数の小さい領域で急激に低下し，負荷荷重 が小さくなるに従いサイクル数の小さな初期段階から 漸次に曲げ強度保持率の低下が生ずる.ささらに負荷荷 重が小さくなると，初期段階では劣化が生じないで, 後期になって少しずつ劣化してくる. Fig. 12 はー50 〜 $75^{\circ} \mathrm{C}$ の温度幅に拈ける同様の変化を示したものであ る. $98 \mathrm{~kg} / \mathrm{mm}^{2}$ が限界曲線上の応力である. 温度幅 が小さくなると，この図に示されるように，限界曲線 上にある負荷荷重に执ける熱サイクル劣化でも, 劣化 はサイクル数に対して徐々に生じて拈り曲げ強度保持 率は漸次に低下する. 負荷荷重を小さくすると, サイ クル数の小さい初期の段階では曲げ強度保持率はほと んぞ変化しない.Fig. 13 は，さらに温度幅が小さい ー 50〜 $50^{\circ} \mathrm{C}$ に和けるサイクル数と曲げ強度保持率の関 係を示したものである. 負荷荷重 $112 \mathrm{~kg} / \mathrm{mm}^{2}$ は限界 曲線上のものである.この場合には，サイクル数の小 さい初期段階に括ける曲げ強度保持率の低下は小さく, 後期のサイクル数が大きい段階になると曲げ強度保持 率は急激に低下する. 負荷荷重が小さくなると, 初期 段階ではほとんど劣化が岕こらず, サイクル数の増大 とともに少しずつ劣化が生じてくる. 以上の結果から， 荷重下の熱サイクル疲労による劣化の傾向をモデル的 に示すと Fig. 14 のよらになる. すなわち, サイクル 数 (時間) に対する劣化 (保持率) は, 曲線 I, II, IIIのタイプに分類できる. タイプIは初期段階ではほ とんど劣化せず，後期になって劣化する上に凸の変化 をするものである. タイプII に劣化する傾向を示するのである. タイプIIIは, 初期 の段階から著しい劣化傾向を示し, 後期には大きな変 化を示さないものである. 以上のよらな観点から，各 温度幅について劣化の傾向を検討すると， $-50 〜 100$

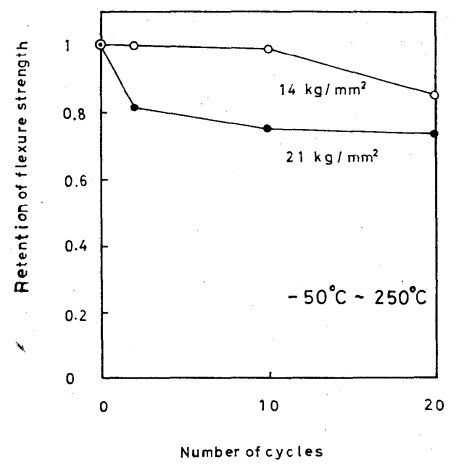

Fig. 9. Change of retention of flexure strength of CFRP with heat cycle fatigue test condition under creep stress at $-50 \sim$ $250^{\circ} \mathrm{C}$.

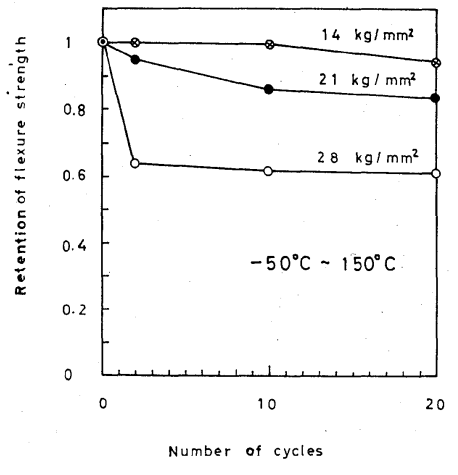

Fig. 10. Change of retention of flexure strength of CFRP with heat cycle fatigue test condition under creep stress at $-50 \sim$ $150^{\circ} \mathrm{C}$.

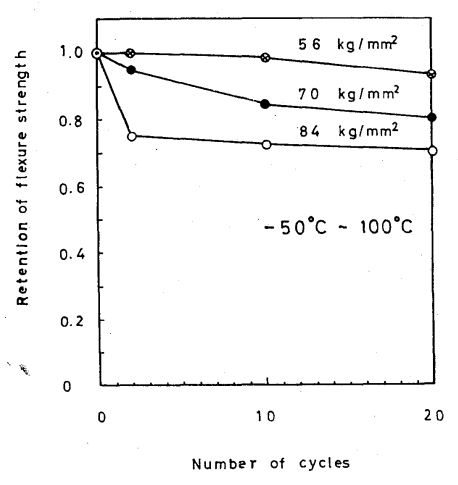

Fig. 11. Change of retention of flexure strength of CFRP with heat cycle fatigue test condition under creep stress at $-50 \sim$ $100^{\circ} \mathrm{C}$. 


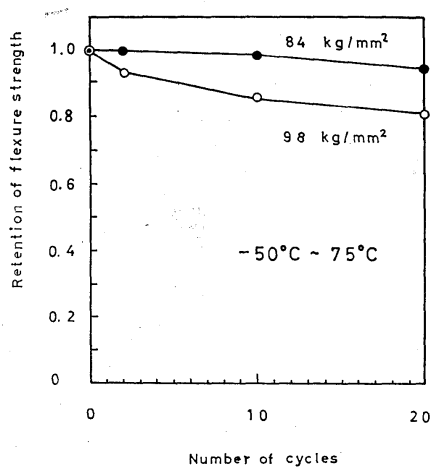

Fig. 12. Change of retention of flexure strength of CFRP with heat cycle fatigue test condition under creep stress at $-50 \sim$ $75^{\circ} \mathrm{C}$.

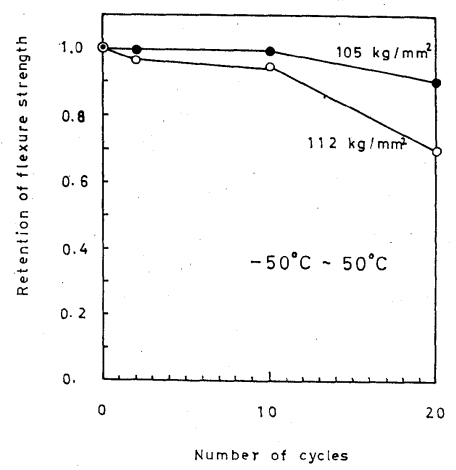

Fig. 13. Change of retention of flexure strength of CFRP with heat cycle fatigue test condition under creep stress at $-50 \sim$ $50^{\circ} \mathrm{C}$.

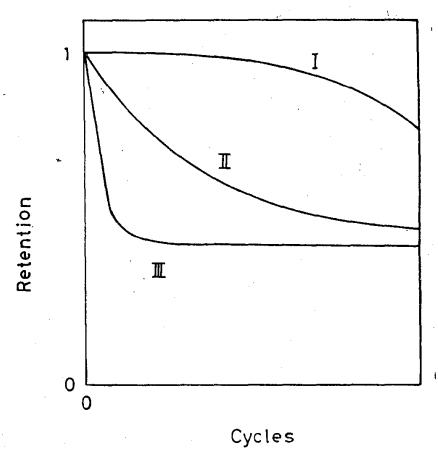

Fig. 14. Degradation types of $\mathrm{CF}$ $\mathrm{RP}$ in heat cycle fatigue test under creep stress.

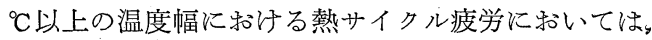
限界曲線付近の負荷荷重では开型を示し，少し負荷荷 重が小さくなると型を示し，さらに負荷荷重が小さ くなるとI 型を示すようになる。 $-50 〜 75^{\circ} \mathrm{C}$ の温度幅 に拈ける熱サイクル疲労に括いては，而型を示さず， 限界曲線上の負荷荷重の場合でも II 型を示し，荷重が 小さくなるとI 型を示すようになるささらに温度幅が 小さい， $-50 \sim 50^{\circ} \mathrm{C}$ に和ける熱サイクル疲労に祘いて は，限界曲線上の荷重でも， III型，II型を示さず I 型 のみを示すようになる。ささら詳細に, 温度幅, 負荷 荷重を変化させて，熱サイクル疲労による劣化のタイ プを検討した結果をFig. 15 に示す. 図中の曲線は荷 重一温度の破壊限界曲線を示す。温度は $-50^{\circ} \mathrm{C}$ からの 温度幅を示す．III型の劣化を示す曲線は, 温度幅が大 きいところの荷重一温度の破壊限界曲線付近飞㐫ら れ，II型は，それよりも多少低温側，低荷重側にあら

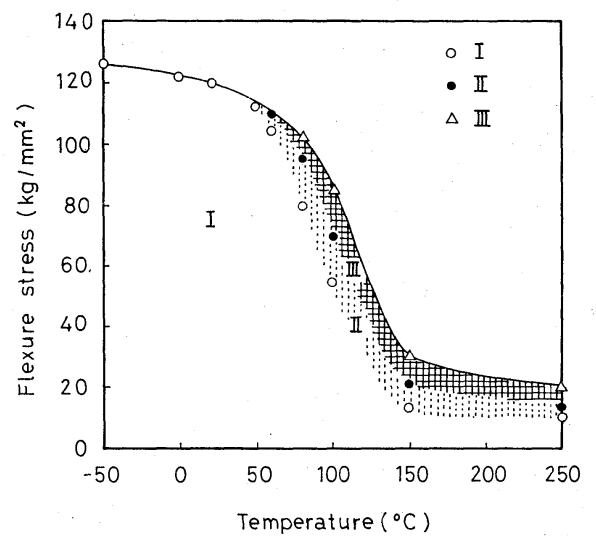

Fig. 15. Regions for different degradation types of CFRP in heat cycle fatigue test on the basis of combination of creep stress and temperature width from $-50^{\circ} \mathrm{C}$.
われ，I 型は低温側，高温側の低荷重側の全領域に㐫 らわれる. 実環境に和ける劣化挙動が而型を示す場合 は，Fig.15 の四型を示す範囲の環境条件で疲労試験 を行えば，促進性とともに類似性の高い促進劣化試験 を行うことができる．同様にII 型の範团に相当する環 境条件抢よび I 型の範囲に相当する環境条件でそれぞ れに対応した劣化試験を行らことにより, 上記と同様 の結果が得られるものと考光られる.

\section{4 結言}

複合材料の耐環境性評価のための要素試験のひとつ とてし荷重条件下の熱サイクル疲労試験機を試作し, CFRP の疲労試験を行った結果, 次のことが明らかに なった.

1.クリープ下熱サイクル条件に敊かれた試料の劣 化は荷重一温度の破壊限界曲線付近に相当する環境に 拈いて最大の值を示す。

2. 温度幅が低温（本実験の場合は $-50^{\circ} \mathrm{C}$ ）から, $T_{\boldsymbol{g}}$ 付近 (本実験の場合 $150^{\circ} \mathrm{C}$ ) 飞执いて最大の劣化が 得られる。

3. クリープ下熱サイクル試験による試料の劣化は, 荷重一温度幅の組合せとより次の挙動を示す。

(1) 初期段階での疲労が顕著なタイプ

(2) 漸減して劣化するタイプ

（3）初期段階での劣化が小さいタイプ

今後の研究に抢いて, 温度幅, 荷重, サイクル数の 詳細な系統化を行い，さらに熱分析等による検討を行 っていく予定である.な抢本研究は，通産省次世代産 業基盤技術研究開発の一環として行われたものである. (昭和59年 3 月 22 日 第13回 FRP シンポジゥムにて講演)

\section{参 考 文 献}

1) Tec. Rep., AFML-TR-74, 266 (1975).

2) NASA-CR-2, 641 (1976). 